\title{
Diabetic Ketoacidosis in an Obese Adolescent Diabetic Patient with Acanthosis Nigricans and without Autoantibodies. Is It Type 1.5 Diabetes?
}

\author{
Abhijit Swami ${ }^{1, *}$, Giridhari Kar², Bijush Difoesa ${ }^{3}$, S G Shyam Lakshman ${ }^{4}$ \\ ${ }^{1}$ Associate Professor of Medicine, Silchar Medical College, Silchar Assam 788015, India \\ ${ }^{2}$ Professor of Medicine Silchar Medical College, Silchar Assam 788015, India \\ ${ }^{3}$ Assistant Professor of Medicine Silchar Medical College, Silchar Assam 788015, India \\ ${ }^{4} \mathrm{PG}$ trainee Silchar Medical College, Silchar Assam 788015, India \\ *Corresponding Author: drabhijitswami@gmail.com
}

Copyright $(2013$ Horizon Research Publishing All rights reserved.

\begin{abstract}
Over the years, adolescents have been diagnosed to be diabetic, the type of which do not fit into the classical types of diabetes - type 1 and type 2. These cases have been reported round the globe. They share features of both types of diabetes like obesity, acanathosis nigricans along with insulin resistance and can even have complications like Diabetic ketoacidosis. The present case study is about a newly diagnosed obese adolescent diabetic patient with acanthosis nigricans presenting with diabetic ketoacidosis who responded to standard treatment of Diabetic ketoacidosis. Subsequently, he was found to have low levels of C-peptide without insulin autoantibodies. Such cases have been variously referred as Double diabetes or 1.5 diabetes in literature and may constitute a subvariant of Diabetes.
\end{abstract}

Keywords Diabetic Ketoacidosis, Acanthosis Nigricans, Type 1.5 Diabetes, Double Diabetes, Glutamate Acid Decarboxylase (GAD) Autoantibodies

\section{Introduction}

Though Diabetes mellitus (DM) has been classified into Type1 DM (T1DM) and Type 2 DM (T2DM) ${ }^{1}$ over the years several cases have been reported which do not fit into the traditional categories of DM. Such forms of DM have gained the attention of the scientific community from the SEARCH study $^{2}$. Recent data from longitudinally followed cohorts have described the clinical features and taxonomy of some of these syndromes that are "intermediate" between T1DM and $\mathrm{T}^{2} \mathrm{DM}^{3}$. The prevalence of both T1DM and T2DM among children and adolescents has been steadily increasing over over the last few decades ${ }^{4}$ However, as the general pediatric population becomes more obese and more ethnically diverse, reliance on phenotypic characteristics for distinguishing between these types of diabetes is becoming increasingly untenable. At the time of diagnosis, it may not be possible to be certain of the type of diabetes in many cases. ${ }^{5}$

\section{Case Report}

A 16 year old adolescent male was admitted in the Medicine ward in an unconscious state. The deterioration of his consciousness occurred over a period of 48 hours and was accompanied by fever, cough, respiratory distress, excessive urination and restlessness. The boy was diagnosed to be a diabetic about a month back and was initiated on insulin Glargine and premeal short acting insulin. His fasting blood glucose at initiation of insulin was $357 \mathrm{mg} / \mathrm{dl}$ and renal function tests were normal. The patient followed the regime for a few days, but had stopped insulin abruptly when he developed mild fever and cough.

There was no family history of diabetes. The boy had sedentary habits and had a history of weight gain of $11 \mathrm{~kg}$ over the last two years.

Examination revealed an obese adolescent with Glasgow Coma Scale of 3/15. His BP was $90 / 60 \mathrm{~mm} \mathrm{Hg}$ and low volume pulse with a rate of $124 / \mathrm{min}$. His tongue was dry and extremities were cold. Oral temperature was $101^{\circ} \mathrm{F}$. He had deep and hurried respiration - respiratory rate $32 / \mathrm{min}$. Chest examination revealed coarse crepitations on left side. He did not have any abdominal organomegaly. His pupils were 3 $\mathrm{mm}$ in diameter and reacted to light. No cranial nerve palsy was detected. He had multiple abdominal striae (Figure 1) and acanthosis nigricans on neck and axilla (Figure 2 and 3).

On admission, his blood glucose level was $654 \mathrm{mg} / \mathrm{dl}$. His blood urea and creatinine levels were normal. Serum sodium and potassium levels were $148 \mathrm{mmol} / \mathrm{L}$ and $5.6 \mathrm{mmol} / \mathrm{L}$ respectively. His blood $\mathrm{pH}$ and bicarbonate levels were $7 \cdot 1$ and $13 \mathrm{mmol} / \mathrm{L}$ respectively. His urine tested positive for acetone. His total leukocyte count was $16,110 / \mathrm{ml}$ with a 
predominance of neutrophils. Chest X-ray showed patchy opacities in the lower lobe of left lung.

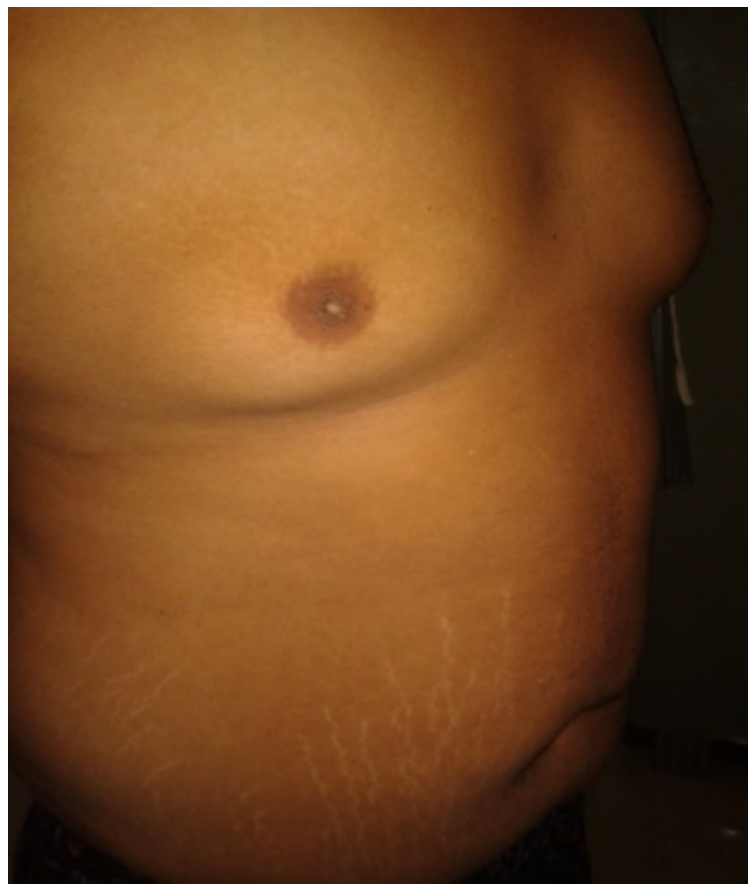

Figure 1. Abdominal striae

The patient was diagnosed to be a case of TIDM with Diabetic ketoacidosis ${ }^{6}$ and pneumonia of left lung. Treatment of DKA was started according to American Diabetic Association (ADA) guidelines ${ }^{1}$ with IV fluids $0.9 \%$ Normal Saline and Ringer's Lactate along with 8 units of short acting Insulin given as IV bolus and 8 units of Insulin given hourly as continuous infusion. Inj Ceftriaxone was given twice daily at a dose of $1 \mathrm{gm}$ IV for pneumonia. An indwelling urethral catheter was placed to measure urinary output.

The patient was monitored intensively with hourly record of blood pressure, urine output and blood glucose. He responded to treatment with improvement of GCS to $15 / 15$ within 12 hours of initiation of treatment. His blood glucose level dropped to $312 \mathrm{mg} / \mathrm{dl}$ and serum potassium level was $4.6 \mathrm{mmol} / \mathrm{l}$ with a blood $\mathrm{pH}$ of 7.34. Urinary acetone was absent.

As the patient had improved and was able to take food orally, oral feeding was initiated along with Inj Glargine and premeal short acting insulin which overlapped the insulin infusion by 6 hours, His blood glucose was $212 \mathrm{mg} / \mathrm{dl}$ within 24 hours of initiation of therapy with normal $\mathrm{pH}$ and potassium values. His lipid profile was normal. Ultrasonography of abdomen did not reveal any organomegaly or pancreatic pathology.

By $3^{\text {rd }}$ day, the patient was ambulatory, afebrile and was able to take care of himself. He weighed $83 \mathrm{~kg}$ with a height of $162 \mathrm{~cm}$. His HbA1C level was $11.6 \%$. The patient improved steadily with treatment and was discharged on Day 7 with a combination of Inj Glargine and premeal short acting Insulin along with counseling and instructions of dose modification according to self blood glucose monitoring.

C-peptide and 8 am Cortisol levels done on follow up at two weeks were $0.78 \mathrm{ng} / \mathrm{dl}$.(Range $-1.10-5.0 \mathrm{ng} / \mathrm{dl}$ ) and 6.67 $\mathrm{pg} / \mathrm{dl}$ (Range 4.30-22 pg/dl)respectively. TSH was $2.45 \mu \mathrm{IU} / \mathrm{ml}$ (Range $0.4-4 \mu \mathrm{IU} / \mathrm{ml}$ ). He tested negative for Glutamate acid decarboxylase autoantibodies (GAD). His fasting blood glucose was $102 \mathrm{mg} / \mathrm{dl}$ and he was following the insulin regime as was advised at the time of discharge. Repeat Chest X-Ray showed resolution of pneumonia.

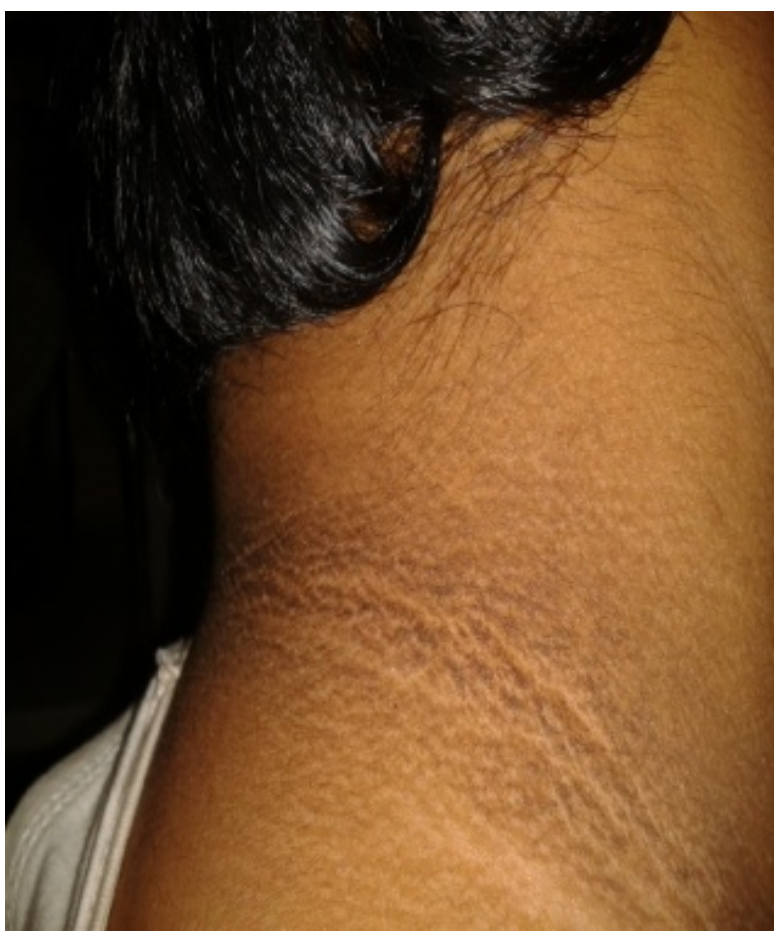

Figure 2. Acanthosis nigricans on neck

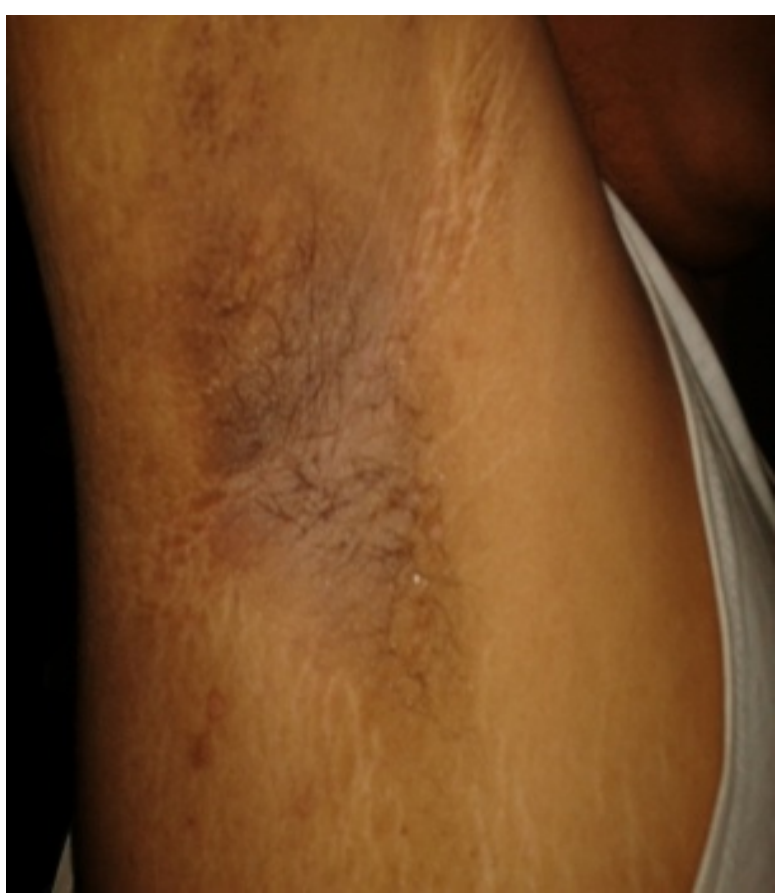

Figure 3. Acanthosis nigricans on axilla 


\section{Discussion}

An episode of DKA was once considered a hallmark feature that would differentiate individuals with T1DM from those with T2DM. This concept was perpetuated by such statements as "patients with NIDDM [non-insulin-dependent diabetes mellitus] are [not] ketosis prone" ${ }^{7}$ and "many individuals with type 2 DM [diabetes mellitus] (previously NIDDM) do not require insulin therapy to prevent ketoacidosis ${ }^{8}$.

Increasingly, reports have emerged from around the world about DKA occuring in phenotypically T2DM patients especially those who are young and obese ${ }^{9}$. Distinctions between T1DM and T2DM are becoming blurred, both etiologically and clinically. A number of studies have suggested that differences between the two types are not always straightforward, and in many cases, a common pathogenic processes may be evident ${ }^{10}$.

Obesity in children may contribute to the escalation of $\beta$-cell destruction, as suggested by the accelerator hypothesis in subjects genetically susceptible to type 1 diabetes ${ }^{11}$. Studies have described a subgroup of children and adolescents with a mixture of the two types of diabetes, i.e., subjects who are obese and/or with signs of insulin resistance as well as positive for markers of autoimmunity to $\beta$-cells ${ }^{12}$. Approximately $70-80 \%$ of newly diagnosed type 1 diabetes patients have autoantibodies to Glutamic Acid Decarboxylase (GAD) 65 and / or IA-2. ${ }^{13}$ while thirty six per cent of the children with T2DM had at least one detectable beta-cell autoantibody in one series. ${ }^{14}$

Thus a gray area has emerged in classification of diabetes especially between obese and adolescent youth who may present with hyperglycemic complications like DKA. The terms "Type 1.5 Diabetes" (T1.5 DM), "Double Diabetes,"(DD), "Latent Autoimmune Diabetes In Youth" (LADY), and "Hybrid Diabetes" characterized by the occurrence of hyperglycemia in overweight/obese children and youth with the combination of markers typical of both T2DM and T1DM, have gained the attention of the scientific community of late. ${ }^{15}$ These subjects are usually obese, may have a family history of diabetes, have a low prevalence of autoimmune markers, and lack HLA genetic association ${ }^{16}$

C-peptide levels have been used to distinguish between T1DM and T2DM in DCCT. A basal C-peptide level $<200$ $\mathrm{pmol} / \mathrm{L}$ was consistent with the diagnosis of type 1 diabetes ${ }^{17}$. Baseline C-peptide levels in the type 1.5 diabetic patients were significantly lower than those in patients classified as T2DM and higher than those in patients classified as $\mathrm{T}_{1} \mathrm{DM}^{14}$. C-peptide levels were found to be below normal or even undetectable at presentation with DKA in Type 1.5 DM and also on follow up after remission. ${ }^{18}$

Though there are multiple etiological factors for Acanthosis nigricans, it has been associated with childhood obesity. ${ }^{19}$ AN has also been described in patients with Type 1.5 Diabetes. ${ }^{20}$

The present case of DKA in an obese adolescent with acanthosis nigricans and low C-peptide levels without autoantibodies and family history of diabetes falls in the category between Type 1 and $2 \mathrm{DM}$ - the type of which is increasingly being reported, but does not find mention in the classification of diabetes by any diabetic association. Such cases are likely to present a clinical and therapeutic challenge to the physicians.

\section{REFERENCES}

[1] ADA Standards of Medical Care in Diabetes-2013 http://care.diabetesjournals.org/content/36/Supplement_1/S1 1.full Diabetes Care January 2013vol. 36 no. Supplement 1 S11-S66

[2] Liu LL, Lawrence JM, Davis C, et al. Prevalence of overweight and obesity in youth with diabetes in USA: the SEARCH for Diabetes in Youth study. Pediatr Diabetes 2010 Pediatr Diabetes. 2010 Feb;11(1):4-11.

[3] Pozzilli P, Guglielmi C, Caprio S, Buzzetti R. Obesity, Autoimmunity, and Double Diabetes in Youth Diabetes Care May 2011 vol. 34 no. Supplement 2 S166-S170

[4] Han JC, Lawlor DA, Kimm SY . Childhood obesity. Lancet 2010;375:1737-1748

[5] Zeitler P. Approach to the obese adolescent with new-onset diabetes.J Clin Endocrinol Metab. 2010 Dec;95(12):5163-70.

[6] Savage MW, Dhatariya KK, Kilvert A,. Rayman G, Rees JAE, Courtney $\mathrm{CH}$, Hilton L,Dyer PH and Hamersley MS: Joint British Diabetes Societies guideline for the management of diabetic ketoacidosis http://www.bsped.org.uk/clinical/docs/JBDSDKAguidelines _May11.pdf

[7] Gregerman RI Diabetes mellitus. Barker LR, Burton JR, Zieve PD eds. Principles of Ambulatory Medicine. 5th ed. Philadelphia, $\mathrm{Pa}$ Lippincott Williams \& Wilkins1999;1023- 1065.

[8] Powers AC Diabetes mellitus. Braunwald E, Fauci A, SIsselbacher KJ et al. eds.Harrison's Principles of Internal Medicine. 15th ed. New York, NY McGraw-Hill Book Co2001;2109- 2137

[9] Valabhji J, Watson M, Cox J, Poulter C, Elwig C, Elkeles RS. Type 2 diabetes presenting as diabetic ketoacidosis in adolescence. Diabet Med. 2003 May;20(5):416-7.

[10] Kolb H, Mandrup-Poulsen T . The global diabetes epidemic as a consequence of lifestyle-induced low-grade inflammation. Diabetologia2010;53:10-20

[11] Wilkin TJ . The accelerator hypothesis: a review of the evidence for insulin resistance as the basis for type I as well as type II diabetes. Int J Obes (Lond) 2009;33:716-726

[12] Pozzilli P, Guglielmi C, Pronina E,Petraikina E . Double or hybrid diabetes associated with an increase in type 1 and type 2 diabetes in children and youths. Pediatr Diabetes 2007;8(Suppl. 9):88-95

[13] Notkins ALand Lernmark A : Autoimmune type 1 diabetes: resolved and unresolved issues J Clin Invest. 2001 November $1 ; 108(9)$ : 1247-1252 
[14] Reinehr T, Schober E, Wiegand S, Thon A, Holl R; DPV-Wiss Study Group. Beta-cell autoantibodies in children with type 2 diabetes mellitus: subgroup or misclassification? Arch Dis Child. 2006 Jun;91(6):473-7.

[15] Badaru A, Pihoker C. Type 2 diabetes in childhood: clinical characteristics and role of $\beta$-cell autoimmunity. Curr Diab Rep. 2012 Feb;12(1):75-81.

[16] Pozzilli P : Double Diabetes : Definition, Diagnosis, Treatment, Prediction

www.sld.cu/.../diabetes/double_diabetes-_definition,_diagno sis, treatment (Accesssed 27/3/13)

[17] The DCCT Research Group: The Diabetes Control and Complications Trial (DCCT) design and methodological considerations for the feasibility phase. Diabetes 1986 ;
$35: 530-45$,

[18] Balasubramanyam A, Nalini R, Hampe CS, and Maldonado M : Syndromes of Ketosis-Prone Diabetes Mellitus Endocr Rev. 2008 May; 29(3): 292-302

[19] Bolding J, Wratchford T, Perkins K, Ogershok P Prevalence of obesity, acanthosis nigricans and hyperinsulinemia in an adolescent clinic. W V Med J. 2005 May-Jun;101(3):112-5.

[20] Purushothaman R, Ramchandani N, Kazachkova I, Ten S Prevalence and clinical features of type 1.5 diabetes mellitus in children. Journal of Pediatric Endocrinology \& Metabolism : JPEM 2007 20(9) Sep pg 981-7 